\title{
The Short-Term Effects of Progressive vs Conventional Core Stability Exercise in Rehabilitation of Nonspecific Chronic Low Back Pain
}

(Kesan Jangka Pendek Senaman Kestabilan Teras Progresif berbanding Konvensional dalam Rehabilitasi Sakit Belakang Kronik yang Tidak Khusus)

\author{
Ebby Waqqash Mohamad Chan, Ali Md NadZAlan, Zainal othman, Eliza Hafiz \& Mohamad Shariff A \\ HAMID*
}

\begin{abstract}
Core stability exercise programs are considered as a fundamental physical therapy treatment for chronic low back pain (LBP). However, it is still unclear which core stability program (progressive vs. conventional) is the most effective. A randomized controlled trial (RCT) was conducted to compare two core stability strategy strategies; progressive dynamic muscular stabilization technique (DMST) and conventional McGill Big 3 (MB3) in the rehabilitation of nonspecific chronic LBP. Thirty males diagnosed with nonspecific chronic LBP patients aged $33.57 \pm 5.28$ years were recruited and randomly assigned to; DMST and MGB3. All patients received additional conventional pain management treatment. The outcome measures were pain severity (motion, standing, sitting), functional disability, trunk endurance, lumbopelvic control, and body balance. All patients were assessed at baseline, 3rd week, and 6th week. A mixed design ANOVA showed both DMST and MGB3 improves all outcomes $(p \leq 0.05)$ specifically the pain severity and functional disability $(p<0.001, \eta p 2=0.81)$, trunk endurance $(p<0.001, \eta p 2=0.30)$, lumbopelvic control $(p<0.001, \eta p 2=$ $0.242)$, and body balance $(p=0.003, \eta p 2=0.46)$ compared to baseline. However, no significant difference was found in all of the outcomes when comparing DMST and MBG3 $(p>0.05)$. In conclusion, both progressive DMST and conventional MGB3 core stability exercise programs are effective for nonspecific chronic LBP rehabilitation.
\end{abstract}

Keywords: Core stability; exercise therapy; low back pain; rehabilitation

\section{ABSTRAK}

Program senaman kestabilan teras dianggap sebagai rawatan terapi fizikal asas untuk sakit belakang (LBP) kronik. Walau bagaimanapun, masih belum jelas program kestabilan teras (progresif berbanding konvensional) adalah yang terbaik. Percubaan terkawal rawak (RCT) telah dijalankan untuk membandingkan dua strategi kestabilan teras; teknik penstabilan otot dinamik (DMST) progresif dan McGill Big 3 (MGB3) konvensional dalam pemulihan LBP kronik yang tidak khusus. Tiga puluh lelaki yang didiagnosis dengan LBP kronik yang tidak khusus berusia $33.57 \pm 5.28$ tahun telah direkrut dan secara rawak dibahagikan kepada DMST dan MGB3. Semua pesakit menerima rawatan tambahan pengurusan sakit konvensional. Keputusan ujian adalah keamatan kesakitan (bergerak, berdiri, duduk), ketidakupayaan berfungsi, ketahanan teras, kawalan 'lumbopelvic' dan keseimbangan badan. Semua pesakit dinilai pada peringkat awal, minggu ke-3 dan minggu ke-6. Dibandingkan pada peringkat awal, kedua-dua kumpulan DMST dan MGB3 bertambah baik dalam semua keputusan ujian $(p \leq 0.05)$ khususnya keamatan kesakitan (bergerak, berdiri, duduk) dan ketidakupayaan berfungsi, $(P<0.001$, $\eta p 2=0.81)$, ketahanan teras $(p<0.001$, $\eta p 2=0.30)$, kawalan 'lumbopelvic' $(p<0.001) \eta p 2=0.242)$ dan keseimbangan badan $(p=0.003, \eta p 2=0.46)$. Walau bagaimanapun, tiada perbezaan yang signifikan dalam semua keputusan ujian apabila dibandingkan antara DMST dan MGB3 (p >0.05). Sebagai kesimpulan, kedua-dua program latihan kestabilan DMST progresif dan MGB3 konvensional berkesan untuk rehabilitasi LBP kronik yang tidak khusus.

Kata kunci: Kestabilan teras; rehabilitasi; sakit belakang bahagian rendah; terapi senaman

\section{INTRODUCTION}

Military personnel are one of the occupations with a high risk of developing low back pain (LBP) due to their job demands. LBP has been a major cause of morbidity and absents from work for the military personnel (Gubata et al. 2014). Current LBP statistics in a Malaysian army base camp showed a high LBP prevalence rate of $48.9 \%$ contributed from high occupational exposure i.e. manual 
equipment handling and job-related physical activities (Chan et al. 2019). High occupational exposure may cause the mediation of initial acute LBP to chronic LBP through mechanical degradation over time (Frost et al. 2019).

Core stability training has been widely used in physical therapy as treatment of low back pain (LBP) (Ortiz et al. 2006; Stuber et al. 2014; Wang et al. 2012). Currently, there is much evidence which suggests the importance of core stabilization in the management of LBP (Ishida et al. 2016; Vera-Garcia et al. 2007). According to Ishida et al. (2016) and Vera-Garcia et al. (2007), improving the deep core strength would promote torso co-contraction, reduce lumbar acceleration and increased lumbar stability during sudden perturbations which is essential for low back injuries prevention. Core stability training re-educates the postural core muscles to stabilize the lumbopelvic region in a neutral state when performing spine-loading tasks (Clark et al. 2011). The lumbopelvichip complex is attached to postural muscles i.e. transverse abdominis, multifidi, and pelvic floor muscles (Brukner \& Khan 2007). These postural muscles are responsible for providing segmental stability and directly controlling the lumbar segments during movement. It has been reported that controlling the lumbar neutral zone decreases the risk of low back injuries and improve self-evaluated workability (Ishida et al. 2016).

One of the commonly used core stability training programs is the McGill Big 3 (MGB3) core stability exercise which was introduced by McGill and Karpowicz (2009). This exercise incorporates abdominal bracing strategy and shown to recruit high trunk muscle activity in an environment that imposes low loads on the spine (McGill \& Karpowicz 2009). The MGB3 exercises composed of three core exercises and have been reported to improve physical function (50-foot preferred speed walk, 50-foot fast walk, and distance walked in five minutes) and active back range of motion (flexion and extension) in patients with chronic LBP (Ammar 2012; Ghorbanpour et al. 2018).

Another lesser-known core stability training program is the dynamic muscular stabilization techniques (DMST) which were introduced by Kumar et al. (2009). The DMST is a 4-stages progressive core stability training program which incorporates both the abdominal hollowing and bracing strategy. The DMST was proven to effective for all chronic LBP patients irrespective of the duration (LBP chronicity; duration of 3-8 months, 9 - 14 months, 21 - 27 months, $\geq 27$ months) (Kumar et al. 2012). Moreover, DMST were effective in improving pain, back strength, abdominal strength, and functional physical ability (walking, stair climbing, stand-ups) (Kumar et al. 2012a, 2012b, 2010, 2009). To the best of our knowledge, no study has compared the progressive DMST and conventional MGB3 core stability exercise. Therefore, a randomized controlled trial (RCT) was conducted for the first time to compare these two core stability training programs on pain severity, functional disability, trunk endurance, lumbopelvic control, and body balance among chronic nonspecific LBP patients.

\section{MATERIALS AND METHODS}

\section{STUDY DESIGN AND PATIENTS}

This study was a single-blind (assessor blinded) parallelgroup randomized controlled trial (RCT) conducted at the Tuanku Mizan Military Hospital. Patients newly diagnosed with LBP at the rehabilitation department were screened for eligibility by the department sports physician and invited to participate in this study. The eligibility criteria for this study are male military personnel aged 18-42 years old (active/in-service) diagnosed with nonspecific chronic LBP (persistence low back pain more than 12 weeks). Patients were excluded if they have specific neurological disorder, history of lumbar spine or abdominal surgery, regular painkiller consumption within 3 months duration, and unable to fulfil follow-up appointments or comply with the rehabilitation program.

This study was approved by the University of Malaya Medical Research Ethics Committee (reference number: 2019122-7025) and Tuanku Mizan Military Hospital Ethics Committee (reference number: HATTM/ EK/19-10). Patients verbal and written consents were attained before the conduct of the study.

\section{SAMPLE SIZE AND RANDOMIZATION}

A priori analysis was conducted for sample size calculation of repeated-measures MANOVA (withinbetween factors) using $\mathrm{G}^{*}$ Power for Windows, version 3.1.7 (Faul et al. 2007). The effect size was derived from the mean and covariance of Kumar et al. (2009) study. The power analysis showed F-test with an effect size (V) of 10.91, alpha and statistical power equal to 0.05 and 0.95 , respectively, with two groups and three repeated measures of 11 outcomes yielded a sample size of 14 patients with an actual power of 1.00. After consideration of dropout rates, a total of 30 patients was recruited in this study.

Thirty eligible patients were randomized to either dynamic muscular stabilization technique (DMST) group or McGill big 3 (MGB3) core stability group. A computergenerated block randomization list ( 2 blocks of 15 patients) was prepared by a colleague who had no clinical involvement in the trial (http://randomizer.org).

\section{STUDY INTERVENTIONS}

After group allocations, patients were either treated with progressive DMST or conventional MGB3 core stability 
exercises. Prior to exercise therapy, all patients received standard pain management therapy treatment two sessions a week for the first 5 weeks. This consists of heat treatment using hydro collator (15 min) and transcutaneous electrical nerve stimulation (TENS) (10 min). Pain management therapy was conducted by physiotherapists in the rehabilitation department. To ensure consistency in pain management therapy, physiotherapists involved in the study attended a one-day training workshop conducted by the investigators.

Patients in the DMST group received progressive DMST training ( 3 exercises, 3 sets, 10 repetitions with 5 s contraction hold) as described by Kumar et al. (2009). The DMST training consists of 4-stages core stability training which progressively increased in intensity on weekly basis: Week 1: Isolation and facilitation of target muscles, Week 2: Training of trunk stabilization under static conditions of increased load, Week 3: Development of trunk stabilization during daily living activities, and Week 4-5: Lumbar stabilization during skilled movements/ occupational demands. The DMST training was performed under the close supervision of the primary investigator.

Patients in the MGB3 group received conventional core stability training ( 3 exercises, 3 sets, 10 repetitions with 5 seconds contraction hold) which was adapted from McGill and Karpowicz (2009). The McGill Big 3 (MGB3) exercises consist of: modified curl-up, kneeling side bridge, and bird dog. The MGB3 training was under the guidance of an exercise science graduate from Universiti Teknologi MARA (UiTM). All patients were informed to only perform the exercise therapy at the rehabilitation department.

\section{BLINDING OF TRAINING ALLOCATION}

Given the intervention involved patients required to perform the DMST and MGB3 exercises, the blinding of the patients was not feasible. However, the assessor who performed the outcome measures was blinded to the treatment patients received. Patients were informed not to disclose details of their treatment. Assessor blinding is considered appropriate to reduce the differential assessment of outcomes (ascertainment bias).

\section{OUTCOME MEASURES}

The effects of treatment were assessed on a different day of intervention at baseline, $3^{\text {rd }}$ week, and $6^{\text {th }}$ week. All assessment was conducted only in the mornings in a room with a standardized temperature of $20-22{ }^{\circ} \mathrm{C}$. Pain severity (in motion, sitting, and standing) and functional disability was the primary outcome measures of this $\mathrm{RCT}$. These variables were measured using the numeric pain rating scale (NRPS) and Malay-version of Roland Morris Disability Questionnaire (RMDQ) (Cardosa et al. 2012). The secondary outcome measures of this RCT were trunk endurance, lumbopelvic control, and body balance. The order of testing was as follows: pain severity and functional disability, lumbopelvic control, body balance, and trunk endurance (trunk flexion $>$ trunk extension $>$ side bridge). Patients were given 5-10 min rest between tests to reduce fatigue and avoid exercise-induced pain (EIP). The overall assessment took between 45-60 min to complete.

The details of NRPS, RMDQ, trunk endurance (trunk flexion, trunk extension, lateral musculature), lumbopelvic control (Sahrmann 5-level core stability test), and body balance (Y-balance test) are summarize as follows.

\section{NUMERIC PAIN RATING SCALE (NRPS)}

The pain severity of the LBP was evaluated independently using NPRS while in motion, standing, and sitting. NPRS is an 11-point scale ranging from $0-10$ where the 0 signifies "no pain" and 10 indicates "the most intense pain imaginable". In a relaxed and comfortable state, patients rated their pain level from a scale of 0 to 10 and filled in the forms provided. Herr et al. (2004) reported that the concurrent validity between NPRS and other scales are high; Visual Analogue scale $(\mathrm{r}=0.86)$, verbal descriptor scale $(\mathrm{r}=0.88), 21$-point Numeric scale $(\mathrm{r}=0.87)$, and faces pain scale $(\mathrm{r}=0.80)$.

\section{ROLAND MORRIS DISABILITY QUESTIONNAIRE (RMDQ)}

The RMDQ is a 24-item self-report questionnaire designed to evaluate the level of function (disability) in activities of daily living for individuals rehabilitating for lower back pain. Each question is worth one point thus scores range from 0 (no disability) to 24 (severe disability). The RMDQ is scored by summing the number of items the patient ticked. Cardosa et al. (2012) reported the Cronbach-alpha of the Malay-translated RMDQ to be 0.88 .

\section{TRUNK ENDURANCE}

The trunk endurance performance of flexion, extension and lateral musculature was measured using a time-based static hold test which the total holding time was recorded (Ito et al. 1996; McGill et al. 1999). The test termination was applied when patients were unable to sustain the specified test position. According to Pozo-Cruz et al. (2014), the receiver-operating curve (ROC) of the trunk endurance tests were reported to be $\geq 0.70$ for men and women. The intraclass correlation coefficients (ICC) of the trunk endurance tests were also reported to be high (ICC: 0.90) (Pozo-Cruz et al. 2014). 
SAHRMANN 5-LEVEL CORE STABILITY TEST

Sahrmann 5-level core stability test (Sahrmann 2002) consists of five levels (level 1 - 5) that progressively increases in difficulty. During the test, an inflatable pad of a Stabilizer Pressure Biofeedback Unit (PBU) is placed in the natural lordotic curve while the patient is lying supine and is inflated to $40 \mathrm{~mm} \mathrm{Hg}$. At each level of the Sahrmann test, the lumbar spine position must be maintained and no more than $10 \mathrm{mmHg}$ change in pressure on the PBU is allowed. The highest level attained for the Sahrmann test was used as the final score. Sahrmann's test performance is significantly correlated with the performance of prone plank test $(\mathrm{Rho}=0.408 ; \mathrm{p}=0.009)$ which may indicate that both tests specifically evaluated the core stability performance in the sagittal plane (Aggarwal et al. 2011).

\section{Y-BALANCE TEST}

The body balance performance was evaluated using the Y-Balance test. This test measures the ability to maintain a single-leg stance while the contralateral leg reaches the anterior, posteromedial, and posterolateral directions (Barati et al. 2013). The reach directions were determined by affixing three tape measures to the floor, one orientated anterior to the apex (A) and two aligned at $135^{\circ}$ in the posteromedial (PM) and posterolateral (PL) directions. Patients were instructed to reach as far as with the one leg in each of the 3 directions while maintaining a singleleg stance. Leg length was used to normalize excursion distances by dividing the distance reached by leg length and then multiplying the result by 100 . Leg length was measured from the anterior superior iliac spine to the most prominent bony point of the ipsilateral medial malleolus with a standard tape measure while patients lay supine on a bed. The final normalized composite reach distance was calculated for each leg as the sum of the maximum reach distance $(\mathrm{cm})$ of all three directions (anterior, posteromedial, and posterolateral), divided 3 times the limb length $(\mathrm{cm})$ and multiplied by 100 (Alnahdi et al. 2015). Previous studies have reported high test-retest reliability of maximal reach distance $(\mathrm{ICC}=0.80-0.85)$ for the 3 reach directions (anterior, posteromedial, and posterolateral) of Y-balance test. (Shaffer et al. 2013).

\section{STATISTICAL ANALYSIS}

Statistical analysis was carried out using IBM SPSS Statistics for Windows, Version 25.0 (Armonk, NY: IBM Corp). Patients contributed to missing data were specified as 999.00. The missing values handled using multiple imputation (MI) method. A priori exploratory data analysis showed all assumptions for parametric statistical methods were fulfilled as most of the data are normally distributed and homogenous.
The descriptive statistics (mean, standard deviation and/or percentage) of age, gender, height, weight, body mass index (BMI), waist to hip ratio (WHR), the branch of services, and military rank were calculated. For inferential statistics, parametric statistical methods $(2 \times 3$ Mixed ANOVA with Greenhouse Geiser correction) was conducted to compare DMST and MGB3 on primary (pain severity and functional disability) and secondary (trunk endurance, body balance, lumbopelvic control) outcome measures in three-time intervals (week 0, 3, 6). The main effects (between-subjects) were evaluated using an independent t-test with Bonferroni correction comparing the intervention groups in the three-time intervals. All inferential analyses conducted were two-tailed with a significant value set at $\mathrm{p} \leq 0.05$.

\section{RESULTS}

Thirty-five patients diagnosed with nonspecific chronic LBP were approached and screened for eligibility. Three $(8.6 \%)$ patients did not fulfil the inclusion criteria (specific diagnosis of LBP - prolapsed intervertebral disc) and another two $(5.7 \%)$ patients declined to participate. Thirty patients $(85.7 \%)$ met the study criteria and underwent randomization (Figure 1).

Twenty-three patients remained at the completion of the study representing $76.6 \%$ retention from baseline. In the MGB3 group, three patients lost to follow-up; one patient in week 4 due to non-adherence to treatment schedule while two patients in week 6 (one patient involved in a motor vehicle accident while the other was transferred out). In the DMST group, a total of 4 patients lost to follow-up in week 6 (three patients did not adhere to treatment schedule while the other was transferred out).

The missing values of the seven patients $(23.4 \%$; 4 in the DMST group; 3 in the MGB3 group) are replaced using multiple imputation (MI) method. This study follows the imputation model restriction rule suggested by Tan et al. (2018) to prevent statistical software crash due to overparameterization. The imputation model for this study is Week 0 and Week 3 as PREDICTORS and Post-test as IMPUTE only with a total of 5 imputations made.

\section{CHARACTERISTICS OF STUDY PATIENTS}

The patients consisted of 30 non-specific chronic LBP patients between the age range of 24 and 42 years. The average age \pm standard deviation (SD) was $33.57 \pm 5.28$ years; the average BMI was $26.23 \pm 3.74(\mathrm{SD}) \mathrm{kg} / \mathrm{m} 2$, and the average WHR was $0.89 \pm 0.05(\mathrm{SD})$. Patients are mostly Malays (83.3\%) with the majority of them had an upper secondary school (73.3\%) as their highest education level. In addition, the majority of patients are in the army military service $(73.3 \%)$ and mostly are in Corporal (46.7\%) rank (Table 1). 


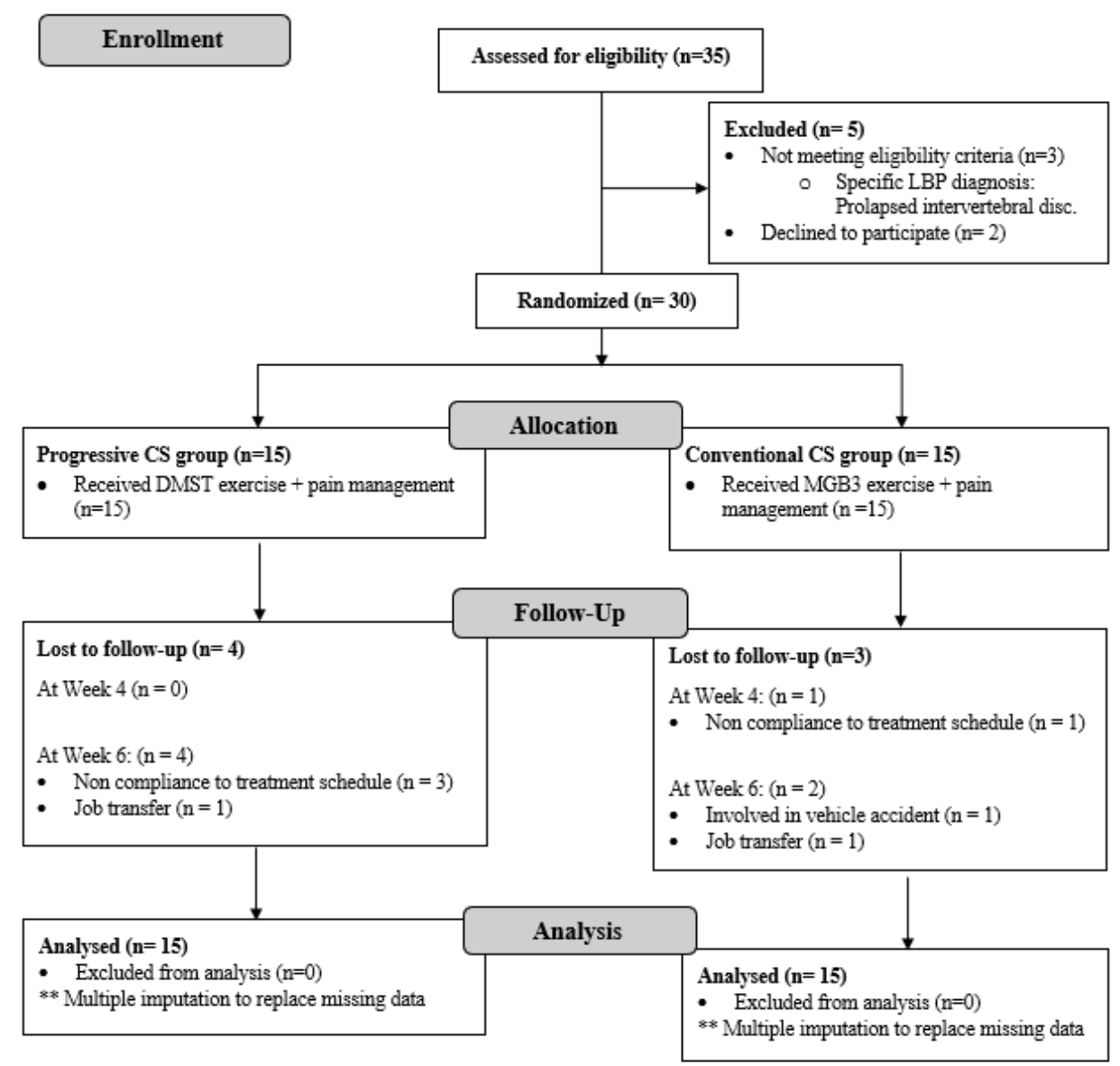

FIGURE 1. Enrolment and randomization of patients

TABLE 1. Patients socio-demographic characteristics

\begin{tabular}{|c|c|c|c|c|}
\hline \multirow[t]{2}{*}{ Characteristics } & \multicolumn{2}{|c|}{$\begin{array}{c}\text { Intervention group } \\
\text { Mean (SD) }\end{array}$} & \multicolumn{2}{|c|}{ T-test } \\
\hline & DMST & MGB3 & $\mathrm{t}$ & P-value \\
\hline Age (years) & $33.3(5.78)$ & 33.8 (4.93) & -0.238 & 0.814 \\
\hline Height $(\mathrm{cm})$ & $1.72(0.07)$ & $1.69(0.05)$ & 0.965 & 0.343 \\
\hline Weight (kg) & 80.04 (16.4) & $73.18(9.52)$ & 1.40 & 0.173 \\
\hline Waist (cm) & $94.7(11.83)$ & $87.33(7.86)$ & 2.008 & 0.054 \\
\hline Hip (cm) & $105.8(10.34)$ & $99.53(6.36)$ & 2.00 & 0.055 \\
\hline $\begin{array}{l}\text { Body mass index } \\
\text { (BMI) }\end{array}$ & $27.01(4.45)$ & $25.45(2.81)$ & 1.147 & 0.261 \\
\hline $\begin{array}{l}\text { Waist-hip-ratio } \\
\text { (WHR) }\end{array}$ & $0.89(0.05)$ & $0.88(0.04)$ & 0.963 & 0.344 \\
\hline
\end{tabular}

Note: $\mathrm{p}$-value $\leq 0.05=$ statistically significant

\section{COMPARISON BETWEEN INTERVENTION GROUPS ON} OUTCOME MEASURES AT BASELINE

At baseline, no significant difference in the sociodemographic background, body profile characteristics and all outcomes were noted between patients in the
DMST and MGB3 group. The Levene's Homogeneity of Variance test also showed that the variances for the outcome measures were mostly homogenous during baseline $(\mathrm{p}>0.05)$ except for trunk flexion and Sahrmann core stability (Table 2). 
TABLE 2. Patients baseline outcome measures comparison between groups

\begin{tabular}{|c|c|c|c|c|}
\hline \multirow{3}{*}{ Outcome measures } & \multicolumn{2}{|c|}{ Intervention group } & \multicolumn{2}{|c|}{ Independent t-test } \\
\hline & DMST & MGB3 & $\mathrm{t}$ & P-value \\
\hline & \multicolumn{2}{|c|}{ Mean (SD) } & & \\
\hline NPRS (motion) & $5.07(1.49)$ & $4.53(2.29)$ & 0.76 & 0.46 \\
\hline NPRS (stand) & $5.87(1.96)$ & $5.8(2.31)$ & 0.85 & 0.93 \\
\hline NPRS (Sit) & $5.47(2.13)$ & $6.07(1.57)$ & -0.88 & 0.39 \\
\hline RMDQ & $12.4(4.27)$ & $10.2(5.20)$ & 1.27 & 0.22 \\
\hline Flexion & $38.6(24.37)$ & $56.73(49.02)$ & -1.28 & 0.21 \\
\hline Extension & $45.2(40.96)$ & $38.2(34.1)$ & 0.51 & 0.62 \\
\hline Right Bridge & $23.93(19.61)$ & $36.67(21.02)$ & -1.72 & 0.10 \\
\hline Left Bridge & $28.2(17.64)$ & $35.7(22.27)$ & -1.03 & 0.31 \\
\hline Right Y-Balance Composite & $68.9(25.02)$ & $78.44(17.79)$ & -1.21 & 0.24 \\
\hline Left Y-Balance Composite & $72.78(17.81)$ & $82.22(10.62)$ & -1.76 & 0.09 \\
\hline Sahrmann Core stability & $0.42(0.62)$ & $0.92(0.97)$ & -1.72 & 0.10 \\
\hline
\end{tabular}

Note: NPRS = Numeric pain rating scale; RMDQ = Roland Morris Disability Questionnaire, $p$ - value $\leq 0.05=$ statistically significant

PRIMARY OUTCOME MEASURES

The $2 \times 3$ mixed ANOVA comparing DMST and MGB3 showed there was significant main effect of treatment (within-subjects) on patient's primary outcomes; pain severity and functional disability (Wilk's $\lambda=0.186$, $\mathrm{F}(8,21)=11.524, \mathrm{p}<0.001, \eta \mathrm{p} 2=0.814)$. However, non-significant interaction between treatment and group (within-between subjects) were found (Wilk's $\lambda=0.854$, $\mathrm{F}(8,21)=0.787, \mathrm{p}=0.681, \eta \mathrm{p} 2=0.213)$. The main effect analysis (between-subjects) showed there were no significant difference between DMST and MGB3 on primary outcomes at all time intervals $(\mathrm{p}>0.05)$ (Figure 2$)$.

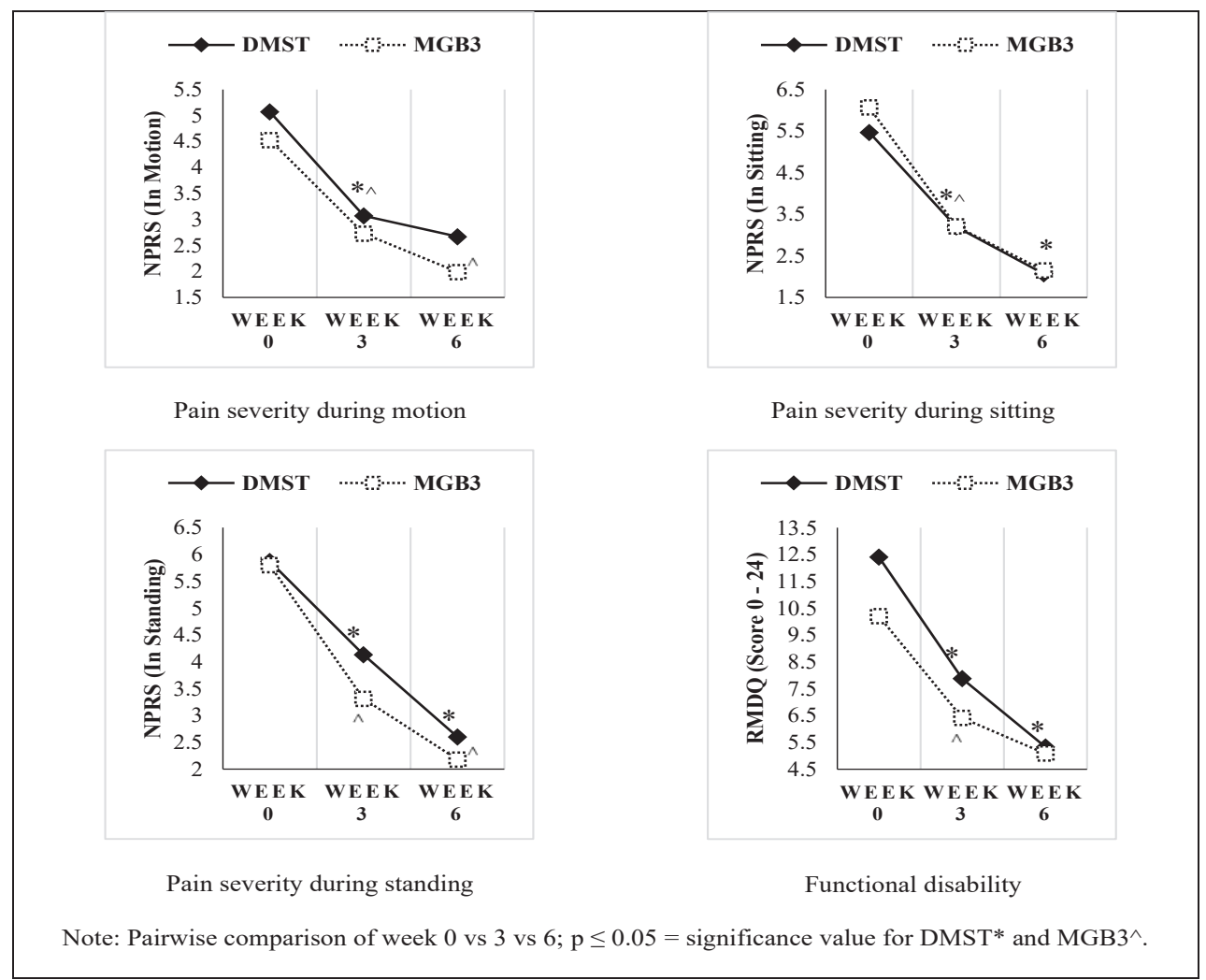

FIGURE 2. Visual illustration of Group*Time on primary outcome measures 


\section{SECONDARY OUTCOME MEASURES}

The comparison of DMST and MGB3 on secondary outcome measures also has significant main effect of treatment (within-subjects); trunk endurance (Wilk's $\lambda=$ $0.496, F(8,106)=5.57, \mathrm{p}<0.001, \eta p 2=0.296$. $)$, Y-balance (Wilk's $\lambda=0.541, \mathrm{~F}(4,25)=5.31, \mathrm{p}=0.003, \eta \mathrm{p} 2=0.459$.), and Sahrmann core stability $(\mathrm{F}(2,56)=11.56, \mathrm{p}<0.001$, $\eta \mathrm{p} 2=0.242$.). However, no significant interaction was found between treatment and group (within-between subjects) for trunk endurance (Wilk's $\lambda=0.854, \mathrm{~F}(8,106)$ $=1.085, \mathrm{p}=0.379, \eta \mathrm{p} 2=0.76)$, Y-Balance (Wilk's $\lambda=$ $0.873, \mathrm{~F}(4,25)=0.909, \mathrm{p}=0.474, \eta p 2=0.127)$, and Sahrmann core stability $(\mathrm{F}(2,56)=1.77, \mathrm{p}=0.263, \eta \mathrm{p} 2$ $=0.047$ ). The main effect analysis (between-subjects) showed no significant difference between DMST and MGB3 on secondary outcomes on at all time intervals ( $>0.05$ ). Figure 3 show graphical presentation of withingroup and between-group changes in score of each variable at baseline, $3^{\text {rd }}$ week and $6^{\text {th }}$ week.
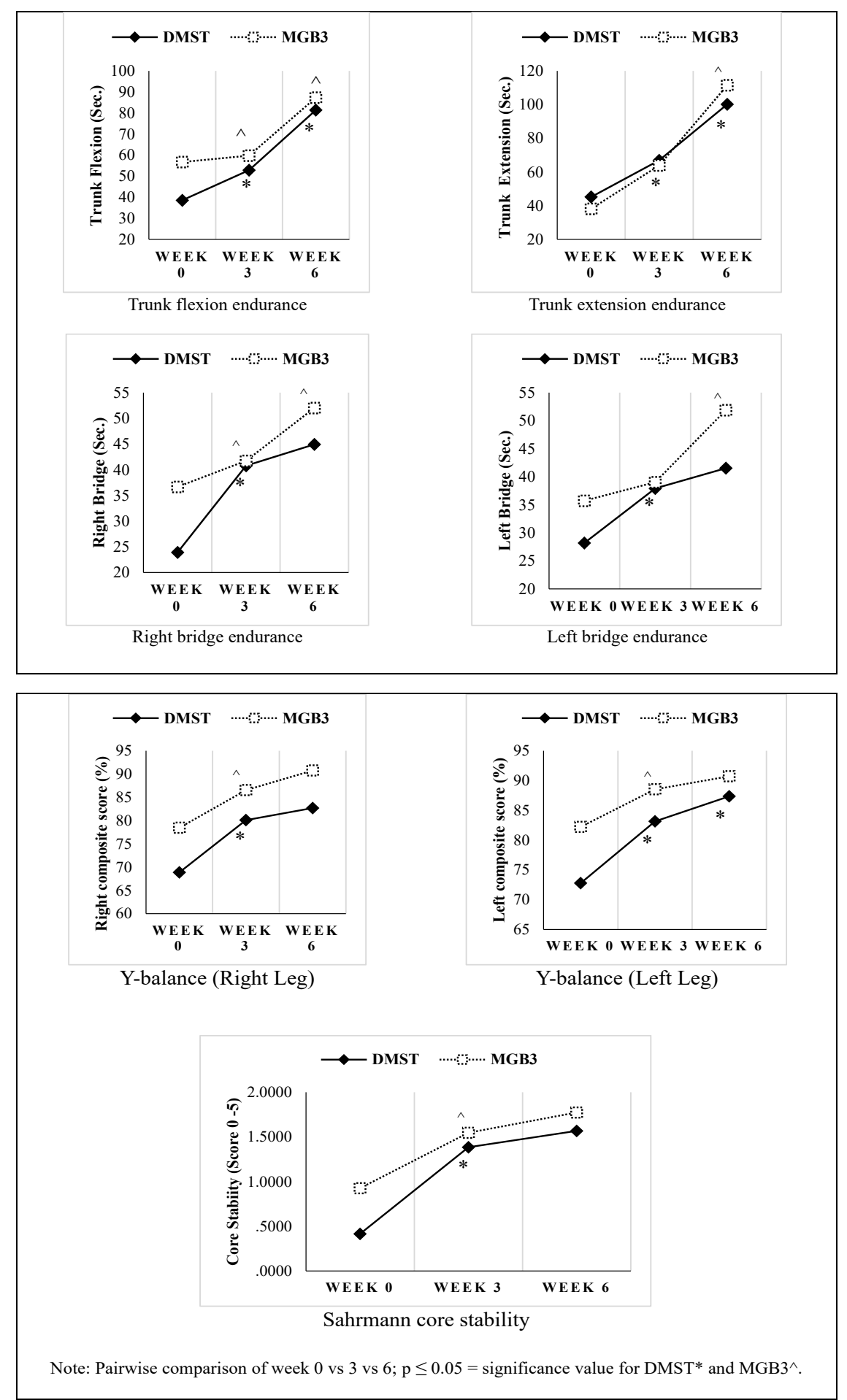

FIGURE 3. Visual illustration of Group*Time on secondary outcome measures 


\section{DISCUSSION}

The present study results clearly indicated that both DMST and MGB3 are equally effective in improving all outcomes measures. There was no significant difference in treatment outcomes when comparing the two core stability interventions at all time points.

Our findings are consistent with previous metaanalysis findings which concluded core stability exercises no more effective than other 'active' treatments in patients with chronic LBP (May \& Johnson 2008; Smith et al. 2014). Smith et al. (2014) reported non-significant difference in pain severity $-3.06(95 \% \mathrm{CI}-6.74$ to 0.63$)$ and functional disability $-1.89(95 \% \mathrm{CI}-5.10$ to 1.33$)$ between core stability exercise program versus other forms of exercise. The current study supports the theory by McGill and Karpowicz (2009) which claims 'any exercise that channels motor patterns to ensure a stable spine, through repetition, constitutes a core stability exercise'. Moreover, functional exercises which resist movements in a lumbar neutral position are a form of core stability strategy (Faries \& Greenwood 2007; Hibbs et al. 2008). Similarly, the DMST incorporates functional core stability strategy from week 3 to 5 .

Subjective evaluation namely the pain severity and functional disability are commonly used measurements for patients subjective perception of their low back pain (Bystrom et al. 2013; Chang et al. 2015; Gomes-Neto et al. 2017; May \& Johnson 2008). The present outcomes showed that both core stability protocol (DMST and MGB3) improves patients pain severity and functional disability. It is suggested that the patients' reduced functional disability in the current study may be contributed by their reduced pain level. Chung et al. (2013) reported a significant relationship between pain severity and functional disability $(\mathrm{p}<0.01, \mathrm{r}=0.53)$. Turner et al. (2004) suggested a 2-point decrease in pain severity from baseline pain index of $\geq 5$ was required to show improvement in functional ability. The present study showed a greater than a 2-point decrease in pain severity for both core stability protocols (DMST and MGB3) which is consistent with the significant decrease in functional disability. The improved pain perception and functional disability in core stability exercises were most likely due to the core muscles preferential activations following training adaptations, thus decreasing any irregular movement of the affected lumbar motion segment (Areeudomwong et al. 2012).

Objective evaluation instruments are necessary to provide quantifiable measures of specific structures involving the treatment outcome (Chang et al. 2015). Trunk endurance performance is one of the essential treatment outcomes because 'slow-twitch type 1' postural core muscles are susceptible to disuse and atrophy in LBP patients (Waldhelm \& Li 2012). The present study demonstrates improvements in trunk endurance for both core stability protocols. Core stability exercise with high repetition and low contraction-hold duration may help develop trunk muscle endurance while minimizing exercise-induced pain (EIP) in chronic LBP patients (McGill \& Karpowicz 2009). The present study adapted McGill and Karpowicz (2009) exercise volume recommendation of 10 repetitions and $5 \mathrm{~s}$ contraction hold.

Both core stability exercise protocols have also been found to improve lumbopelvic control and body balance. It is suggested that these two performance outcome evaluates the neuromuscular function (Hibbs et al. 2008). The specific adaptation to imposed demand (SAID) principle can be observed in this result. The SAID principle defines that the human body adapts to a specific type of training (Lambert et al. 2009). Evidence shows that core stability exercise is specific training to improve neuromuscular function specifically in the recruitment of the transverse abdominis (Bruno 2014; Ferreira et al. 2010). It should also be noted that both DMST and MGB3 protocols were combined with pain management therapy (TENS and heat treatment) to reduce exercise-induced pain (EIP). Pain management is a necessity in the present study because the accumulation of endogenous algesic substances and increased intramuscular pressure from EIP may constitute to reduce exercise performance and reduce patients attrition rate (Astokorki \& Mauger 2017). GomesNeto et al. (2017) advised that core stability exercise must be performed together with pain management for optimal effectiveness in LBP rehabilitation. This suggests that it was the entire package of intervention (core stability exercise and pain management) that was effective rather the core stability exercise alone.

The present study has several limitations to be addressed. Firstly, this study is limited to not having an 'inactive' treatment as a control group due to ethical reasons. This may affect the overall results of the present study as the previous meta-analysis has reported that core stability exercises were consistently significantly better when compared to 'inactive treatments' (May \& Johnson 2008). Secondly, this study does not exclude patients with a history of lower limb injuries which may affect the body balance results. It is not possible to exclude patients with a history of lower limb injuries because of the high incidence rate of multiple musculoskeletal disorders in the Malaysian military population. Thirdly, week 5-6 of this RCT is the starting of the fasting month which may have contributed to higher dropout rates $(n=6)$. The patients' motivation may also have been influenced during this study period. Lastly, the intervention was only for short-term (5 weeks' duration) and there was no long-term follow-up with the patients which could determine the long-term effects of core stability exercise programs particularly in injury prevention. 
Based on the knowledge gained in conducting the present study, several recommendations for future studies are derived. The core stability exercise programs in the present study were effective for the short-term duration (5 weeks). However, future study of longer follow-up is much recommended. A longer follow-up is essential because the risk of recurrence low back pain is great, especially with the high occupational demands in the military population. Furthermore, future core stability intervention study on LBP with different chronicity is also suggested to establish further establish the effectiveness of core stability exercise in chronic LBP rehabilitation.

Practical implications include incorporating both core stability strategy in low back pain rehabilitation i.e. DMST for intensive physiotherapy and MGB3 as home exercise. The training recommendation is based on the justification of both core stability protocols. The DMST protocol involves specific and functional movements which change every week; therefore, physiotherapist supervision will be required. In contrary, the MGB3 consists of only 3 basic static exercises which can be performed by patients without any supervision.

\section{CONCLUSION}

It is concluded that both DMST and MGB3 with pain management are equally effective in improving pain severity, functional disability, trunk endurance, lumbopelvic control, and body balance. Core stability training is an effective treatment approach for chronic nonspecific LBP patients. The selection of core stability training method (conventional vs. progressive) should be dependent on patients' compliance and adherence.

\section{REFERENCES}

Aggarwal, A., Kumar, S., Madan, R. \& Kumar, R. 2011. Relationship among different tests of evaluating low back core stability. Journal of Musculoskeletal Research 14(2): $1-9$.

Alnahdi, A.H., Alderaa, A.A., Aldali, A.Z. \& Alsobayel, H. 2015. Reference values for the $Y$ Balance Test and the lower extremity functional scale in young healthy adults. Journal of Physical Therapy Science 27(12): 3917-3921.

Ammar, T.A. 2012. McGill exercises versus conventional exercises in chronic low back pain. Life Science Journal 9(2): 393-397.

Areeudomwong, P., Puntumetakul, R., Jirarattanaphochai, K., Wanpen, S., Kanpittaya, J., Chatchawan, U. \& Yamauchi, J. 2012. Core stabilization exercise improves pain intensity, functional disability and trunk muscle activity of patients with clinical lumbar instability: A pilot randomized controlled study. Journal of Physical Therapy Science 24(10): 10071012.

Astokorki, A.H.Y. \& Mauger,A.R. 2017. Transcutaneous electrical nerve stimulation reduces exercise-induced perceived pain and improves endurance exercise performance. European Journal of Applied Physiology 117(3): 483-492.
Barati, A., Safarcherati, A., Aghayari, A. Azizi, F. \& Abbasi, H. 2013. Evaluation of relationship between trunk muscle endurance and static balance in male students. Asian Journal of Sports Medicine 4(4): 289-294.

Brukner, P. \& Khan, K. 2007. Core stability. In Clinical Sports Medicine, edited by Brukner, P. \& Khan, K. Sydney: McGraw-Hill. pp. 158-173.

Bruno, P. 2014. The use of "stabilization exercises" to affect neuromuscular control in the lumbopelvic region: A narrative review. The Journal of the Canadian Chiropractic Association 58(2): 119-130.

Bystrom, M.G., Rasmussen-Barr, E. \& Grooten, W.J.A. 2013. Motor control exercises reduces pain and disability in chronic and recurrent low back pain: A meta-analysis. Spine 38(6): E350- E358.

Cardosa, M., Osman, Z.J., Nicholas, M., Tonkin, L., Williams, A., Abd Aziz, K., Mohd Ali, R. \& Dahari, N.M. 2012. Self-management of chronic pain in Malaysian patients: Effectiveness trial with 1-year follow-up. Translational Behavioral Medicine 2(1): 30-37.

Chan, E.W.M., Hamid, M.S.A., Din, F.H.M., Ahmad, R. Nadzalan, A.M. \& Hafiz, E. 2019. Prevalence and factors associated with low back pain among Malaysian army personnel stationed in Klang Valley. Biomedical Human Kinetics 11(1): 9-18.

Chang, W.D., Lin, H.Y. \& Lai, P.T. 2015. Core strength training for patients with chronic low back pain. Journal of Physical Therapy Science 27(3): 619-622.

Chung, E.J., Hur, Y.G. \& Lee, B.H. 2013. A study of the relationship among fear-avoidance beliefs, pain and disability index in patients with low back pain. Journal of Exercise Rehabilitation 9(6): 532-535.

Clark, M., Hoogenboom, B.J. \& Bennet, J.I. 2011. Establishing core stability in rehabilitation. In Rehabilitation Techniques for Sports Medicine and Athletic Training, edited by Prentice, W.E. New York: McGraw-Hill. pp. 98-121.

Faries, M.D. \& Greenwood, M. 2007. Core training: Stabilizing the confusion. Strength \& Conditioning Journal 29(2): 10-25.

Faul, F., Erdfelder, E., Lang, A.G. \& Buchner, A. 2007. G*Power 3: A flexible statistical power analysis program for the social, behavioral, and biomedical sciences. Behavior Research Methods 39(2): 175-191.

Ferreira, P.H., Ferreira, M.L., Maher, C.G., Refshauge, K., Herbert, R.D. \& Hodges, P.W. 2010. Changes in recruitment of transversus abdominis correlate with disability in people with chronic low back pain. British Journal of Sports Medicine 44(16): 1166-1172.

Frost, B.A., Camarero-Espinosa, S. \& Foster, E.J. 2019. Materials for the spine: Anatomy, problems, and solutions. Materials (Basel) 12(2): 253.

Ghorbanpour, A., Azghani, M.R., Taghipour, M., Salahzadeh, Z., Ghaderi, F. \& Oskouei, A.E. 2018. Effects of McGill stabilization exercises and conventional physiotherapy on pain, functional disability and active back range of motion in patients with chronic non-specific low back pain. Journal of Physical Therapy Science 30(4): 481-485.

Gomes-Neto, M., Lopes, J.M., Conceição, C.S., Araujo, A., Brasileiro, A., Sousa, C., Carvalho, V.O. \& Arcanjo, F.L. 2017. Stabilization exercise compared to general exercises 
or manual therapy for the management of low back pain: A systematic review and meta-analysis. Physical Therapy in Sport 23: 136-142.

Gubata, M.E., Piccirillo, A.L., Packnett, E.R., Niebuhr, D.W., Boivin, M.R. \& Cowan, D.N. 2014. Risk factors for backrelated disability in the US army and marine corps. Spine 39(9): 745-753.

Herr, K.A., Spratt, K., Mobily, P.R. \& Richardson, G. 2004. Pain intensity assessment in older adults: Use of experimental pain to compare psychometric properties and usability of selected pain scales with younger adults. Clinical Journal of Pain 20(4): 207-219.

Hibbs, A.E., Thompson, K.G., French, D., Wrigley, A. \& Spears, I. 2008. Optimizing performance by improving core stability and core strength. Sports Medicine 38(12): 995-1008.

Ishida, H., Suehiro, T., Kurozumi, C. \& Watanabe, S. 2016. Comparison between the effectiveness of expiration and abdominal bracing maneuvers in maintaining spinal stability following sudden trunk loading. Journal of Electromyography and Kinesiology 26: 125-129.

Ito, T., Shirado, O., Suzuki, H., Takahashi, M., Kaneda, K. \& Strax, T.E. 1996. Lumbar trunk muscle endurance testing: An inexpensive alternative to a machine for evaluation. Archives of Physical Medicine and Rehabilitation 77(1): 75-79.

Kumar, S., Sharma, V.P., Aggarwal, A., Shukla, R. \& Dev, R. 2012a. Effect of dynamic muscular stabilization technique on low back pain of different durations. Journal of Back and Musculoskeletal Rehabilitation 25(2): 73-79.

Kumar, S., Sharma, V.P., Shukla, R., Dev, R. \& Aggarwal, A. 2012b. Efficacy of dynamic muscular stabilization techniques in the management of lumbar disc disorders. Nigerian Journal of Medical Rehabilitation 14(1 \& 2): 13-19.

Kumar, S., Sharma, V.P., Shukla, R. \& Dev, R. 2010. Comparative efficacy of two multimodal treatments on male and female sub-groups with low back pain (part II). Journal of Back and Musculoskeletal Rehabilitation 23(1): 1-9.

Kumar, S., Sharma, V.P. \& Negi, M.P. 2009. Efficacy of dynamic muscular stabilization techniques (DMST) over conventional techniques in rehabilitation of chronic low back pain. Journal of Strength and Conditioning Research 23(9): 2651-2659.

Lambert, M., Viljoen, W., Bosch, A., Pearce, A. \& Sayers, M. 2009. General principles of training. In The Olympic Textbook of Medicine in Sport, edited by Schwellnus, M.P. Oxford: Wiley-Blackwell. pp. 1-48.

May, S. \& Johnson, R. 2008. Stabilisation exercises for low back pain: A systematic review. Physiotherapy 94(3): 179-189.

McGill, S.M., Childs, A. \& Liebenson, C. 1999. Endurance times for low back stabilization exercises: Clinical targets for testing and training from a normal database. Archives of Physical Medicine and Rehabilitation 80(8): 941-944.

McGill, S.M. \& Karpowicz, A. 2009. Exercises for spine stabilization: Motion/motor patterns, stability progressions, and clinical technique. Archives of Physical Medicine and Rehabilitation 90(1): 118-126.

Ortiz, A., Olson, S. \& Libby, C.L. 2006. Core stability in the female athlete: A review. Journal of Women's Health Physical Therapy 30(2): 11-17.
Pozo-Cruz, B.d., Mocholí, M.H., Pozo-Cruz, J.d., Parraca, J.A., Adsuar, J.C. \& Gusi, N. 2014. Reliability and validity of lumbar and abdominal trunk muscle endurance tests in office workers with nonspecific subacute low back pain. Journal of Back and Musculoskeletal Rehabilitation 27(4): 399-408.

Sahrmann, S. 2002. Diagnosis and Treatment of Movement Impairment Syndromes. 1st ed. St. Louise: Mosby.

Shaffer, S.W., Teyhen, D.S., Lorenson, C.L., Warren, R.L., Koreerat, C.M., Straseske, C.A. \& Childs, J.D. 2013. Y-balance test: A reliability study involving multiple raters. Military Medicine 178(11): 1264-1270.

Smith, B.E., Littlewood, C. \& May, S. 2014. An update of stabilisation exercises for low back pain: A systematic review with meta-analysis. BMC Musculoskeletal Disorders 15(1): 416

Stuber, K.J., Bruno, P., Sajko, S. \& Hayden, J.A. 2014. Core stability exercises for low back pain in athletes: A systematic review of the literature. Clinical Journal of Sport Medicine 24(6): 448-456.

Tan, F.E.S., Jolani, S. \& Verbeek, H. 2018. Guidelines for multiple imputations in repeated measurements with time-dependent covariates: A case study. Journal of Clinical Epidemiology 102: 107-114.

Turner, J.A., Franklin, G., Heagerty, P.J., Wu, R., Egan, K., Fulton-Kehoe, D., Gluck, J.V. \& Wickizer, T.M. 2004. The association between pain and disability. Pain 112(3): $307-$ 314.

Vera-Garcia, F.J., Elvira, J.L.L., Brown, S.H.M. \& McGill, S.M. 2007. Effects of abdominal stabilization maneuvers on the control of spine motion and stability against sudden trunk perturbations. Journal of Electromyography and Kinesiology 17(5): 556-567.

Waldhelm, A. \& Li, L. 2012. Endurance tests are the most reliable core stability related measurements. Journal of Sport and Health Science 1(2): 121-128.

Wang, X.Q., Zheng, J.J., Yu, Z.W., Bi, X., Lou, S.J., Liu, J., Cai, B., Hua, Y.H., Wu, M., Wei, M.L., Shen, H.M., Chen, Y., Pan, Y.J., Xu, G.H. \& Chen, P.J. 2012. A meta-analysis of core stability exercise versus general exercise for chronic low back pain. PLOS ONE 7(12): e52082.

Ebby Waqqash, Mohamad Chan \& Eliza Hafiz

Centre of Sports \& Exercise Sciences

University of Malaya

50603 Kuala Lumpur, Federal Territory

Malaysia

Ali Md Nadzalan

Faculty of Sports Science and Coaching

Universiti Pendidikan Sultan Idris

35900 Tanjong Malim, Perak Darul Ridzuan

Malaysia

Zainal Othman

Rehabilitation Department

Tuanku Mizan Military Hospital

53300 Kuala Lumpur, Federal Territory

Malaysia 
Mohamad Shariff A. Hamid*

Faculty of Medicine

University of Malaya

50603 Kuala Lumpur, Federal Territory

Malaysia
*Corresponding author; email: ayip@um.edu.my

Received: 16 February 2020

Accepted: 3 May 2020 